\title{
Maximal bite force in young adults with temporomandibular disorders and bruxism
}

\author{
Força de mordida máxima em adultos jovens \\ com disfunção temporomandibular e bruxismo
}

\begin{abstract}
Raquel Aparecida Pizolato(a) Maria Beatriz Duarte Gavião(b) Giédre Berretin-Felix ${ }^{(c)}$

Ana Claudia Martins Sampaio(d) Alceu Sergio Trindade Junior ${ }^{(\mathrm{e})}$
\end{abstract}

\footnotetext{
(a) Graduate Student, Department of Physiological Sciences; (b)Professor, Department of Pediatric Dentistry - School of Dentistry of Piracicaba, State University of Campinas.

(c) Assistant Professor, Department of Speech Pathology and Audiology; (e)Professor, Department of Biological Sciences - School of Dentistry of Bauru, University of São Paulo.

(d) Physiologist, Foundation for the Study and Treatment of Craniofacial Anomalies, Physiology Laboratory, University of São Paulo, Bauru, SP, Brazil.
}

\begin{abstract}
Parafunctional habits, such as bruxism, are contributory factors for temporomandibular disorders (TMD). The aim of this study was to evaluate the maximal bite force $(\mathrm{MBF})$ in the presence of TMD and bruxism (TMDB) in young adults. Twelve women (mean age 21.5 years) and 7 men (mean age 22.4 years), composed the TMDB group. Ten healthy women and 9 men (mean age 21.4 and 22.4 years, respectively) formed the control group. TMD symptoms were evaluated by a structured questionnaire and clinical signs/symptoms were evaluated during clinical examination. A visual analogical scale (VAS) was applied for stress assessment. MBF was measured with a gnatodynamometer. The subjects were asked to bite 2 times with maximal effort, during 5 seconds, with a rest interval of about one minute. The highest values were considered. The data were analyzed with ShapiroWilks W-test, descriptive statistics, paired or unpaired $t$ tests or Mann-Whitney tests when indicated, and Fisher's exact test $(\mathrm{p}<0.05)$. TMDB women presented lower values of MBF as compared to those presented by TMDB men and by the control group. MBF for TMDB men was similar to that of the control group. The proportion of TMDB women with muscle pain and facial/teeth/head pain upon waking up was significantly higher than that of men. Control women presented significantly lower stress scores than the others. It was concluded that MBF was reduced in TMDB women, as they presented more signs and symptoms. Men presented higher MBF values than women, but TMD and bruxism did not significantly decrease MBF. Stress was not an influencing factor for TMD and bruxism in men.
\end{abstract}

Descriptors: Temporomandibular joint disorders; Bruxism; Bite force.

Resumo: Hábitos parafuncionais, como o bruxismo, podem contribuir para a disfunção temporomandibular (DTM). O objetivo deste trabalho foi avaliar a força de mordida máxima (FMM) na presença de DTM e bruxismo (DTMB) em adultos jovens. Doze mulheres (idade média de 21,5 anos) e sete homens (idade média 22,4 anos) compuseram o grupo DTMB. O grupo controle foi formado por 10 mulheres e 9 homens saudáveis, com idades médias de 21,4 e 22,4 anos, respectivamente. Os sintomas de DTM foram avaliados com um questionário estruturado, e os sinais/sintomas clínicos foram avaliados no exame clínico. Para avaliar estresse, utilizou-se a escala analógica visual (VAS). A FMM foi mensurada com gnatodinamômetro, e o participante foi orientado a morder com o máximo esforço durante 5 segundos, duas vezes, com intervalo de aproximadamente 1 minuto, considerando-se os valores máximos. Os dados foram analisados pelo teste de ShapiroWilks, estatística descritiva, teste $t$ pareado e independente, Mann-Whitney e exato de Fisher $(\mathrm{p}<0,05)$. As mulheres do grupo DTMB apresentaram FMM menor que os homens do grupo DTMB e do grupo controle. A FMM entre os homens do grupo DTMB foi similar à do grupo controle. A proporção de mulheres no Grupo DTMB com dor muscular e em face/dentes/cabeça ao acordar foi significativamente maior do que a proporção de homens. As mulheres do grupo controle apresentaram escores do estresse significativamente menores. Concluiu-se que a FMM foi reduzida em mulheres com DTM e bruxismo devido ao maior número de sinais e sintomas. Os homens apresentaram maior FMM do que as mulheres, mas a presença de DTM e bruxismo não diminuiu significativamente a FMM. O estresse não influenciou a presença de DTM e bruxismo nos homens.

Descritores: Transtornos da articulação temporomandibular; Bruxismo; Força de mordida. 


\section{Introduction}

The temporomandibular disorder (TMD) is considered a heterogeneous group of psychophysiological disturbances involving facial pain and/or masticatory dysfunction as common characteristics. ${ }^{24}$ Although its etiology has been considered multifactorial, ${ }^{13}$ the relative importance of individual factors is still controversial. Psychosocial variables may play an important role in adaptation to pain and eventual recovery. TMD patients exhibit a variety of psychological and behavioral characteristics, including increased somatization, stress, anxiety and depression. ${ }^{20}$

Parafunctional habits are considered contributory factors for TMD manifestation. The main parafunctional habit involved is bruxism, which is classified as parafunction because it does not have a functional objective, such as mastication, phonation, or deglutition. ${ }^{27}$ Bruxism is an involuntary masticatory muscle activity that is characterized by clenching and/or grinding of the teeth. ${ }^{3}$ Tooth clenching occurs in most episodes of diurnal bruxism, while in nocturnal bruxism, both clenching and grinding are observed. ${ }^{16}$ Bruxism has a prevalence of about $10 \%$ in the general adult population, and is usually regarded as one of the possible causative factors, among others, of temporomandibular pain, tooth wear in the form of attrition, and loss of dental implants. ${ }^{18}$ Two groups of proposed etiological factors can be distinguished: peripheral (morphological) and central (pathophysiological and psychological). At present, peripheral morphological factors, e.g. occlusal discrepancies, are considered to play a minor role, if any, whilst central factors, such as disorders in the dopaminergic system and stress, have been suggested as more important in this disorder. Smoking and alcohol consumption have also been linked to bruxism, and studies suggest that age, gender and genetic factors may influence its prevalence. ${ }^{2,16}$ In short, bruxism is mainly centrally - not peripherally - mediated..$^{18}$

In bruxers, the distribution of muscle forces to the teeth and to the temporomandibular joints (TMJ) may result in tooth wear and orofacial pain, as well as hyperactivity and hypertrophy of the masticatory muscles, especially the masseter. ${ }^{7}$ Nevertheless, some authors question the role of bruxism as a causal agent of tooth wear, ${ }^{4}$ while others suggest that increased tooth wear is related to bite force ${ }^{14}$ and parafunctional habits. ${ }^{19}$

The maximal bite force is the effort exerted between the maxillary and mandibular teeth when the mandible is elevated by the masticatory muscles. ${ }^{2}$ The relationship between high levels of bite force and the presence of bruxism is a controversial issue in the related literature. It has been suggested that subjects with bruxism have overtrained masticatory muscles, leading to hypertrophy and higher bite force, ${ }^{21}$ but no higher levels of bite force during episodes of sleep bruxism ${ }^{26}$ were found. One study showed that young dentate adult bruxers and nonbruxers did not present different voluntary maximum bite force values. ${ }^{8}$ However, patients with TMD have been reported to have lower values than healthy subjects. ${ }^{2,6}$

The aim of this study was to evaluate the voluntary maximal bite force (MBF) in the presence of bruxism and TMD in a sample of young adults.

\section{Material and Methods Sample}

A convenience sample of 19 adults aged from 19 to 31 years (12 women, mean age 21.5 years; 7 men, mean age 22.4 years), with history of TMD and bruxism, was selected (TMDB group). The matched controls were 19 healthy subjects in the same age range (10 women, mean age 21.4 years; 9 men, mean age 22.4 years) (Control group). They were recruited and selected from the dental student body and from the staff of the Department of Prosthodontics, School of Dentistry of Bauru, State University of São Paulo, Bauru, SP, Brazil. All subjects participated voluntarily and provided a written informed consent. The Ethics Committee of the Craniofacial Anomalies Hospital, University of São Paulo, approved the research. The exclusion criteria were: history of oral and maxillofacial surgery, orthodontic treatment, TMD treatment and use of medicines at the moment of the research, removable or fixed partial or total oral prosthesis, large facial skeletal alterations (typical Class II and Class III individuals), and treatment with regard to occlusal splint. The inclusion criteria comprised subjects with complete dentition and normal dental occlusion with simultaneous bilateral contact. 


\section{TMD and bruxism symptoms}

All subjects answered a structured questionnaire, adapted from Fonseca ${ }^{11}$ (1992), to assess the symptoms with regard to pain in the jaws when functioning (e.g. chewing), unusually frequent headaches (more than once a week and with unknown etiology), difficulty in opening the mouth wide, sounds from the TMJ, and facial/tooth/head pain upon waking up. Questions about oral parafunction comprised toothclenching, tooth-grinding at night, and oral habits such as biting nails, lip, cheek, and/or foreign objects. The variable bruxism was constructed by combining daytime tooth-clenching and/or tooth-grinding at night. Each question could be answered with "yes" or "no". A visual analogical scale (VAS) for stress ranging from 0 to 10 was applied individually.

\section{Clinical signs of TMD}

The signs of TMD were assessed by one calibrated examiner in accordance with the criteria proposed by Dworkin, Le Resche ${ }^{10}$ (1992). A standardized clinical examination evaluated TMJ sounds and pain during mandibular movements, and TMJ and muscle pain upon palpation. The TMJ was palpated laterally and posteriorly via the auditory meatus. The muscles palpated were the origin and insertion of the temporal muscle, of the medial pterygoid muscle, of the superficial portion of the masseter muscle, and of the sternocleidomastoideus muscle. All muscles were palpated bilaterally, with a standard pressure of about $1,000 \mathrm{~g}$.

\section{Maximal bite force (MBF) measurement}

To measure MBF, a gnatodynamometer with two strain gages and having $10 \mathrm{~mm}$ in height and $10 \mathrm{~mm}$ in diameter was used (KFG-1-D16-11 Kyowa Electronic Instruments CO., LTD., Tokyo, Japan). The subjects received detailed experimental instructions and tested biting the equipment several times before the actual recordings were made to build confidence in the test procedure. Next, each subject was asked to bite the device 2 times with maximal effort, during 5 seconds, with a rest interval between trials of about one minute. The bite force was recorded in Kgf and converted to Newton. The highest values between two trials were considered as the subject's MBF.

\section{Statistical analysis}

The Shapiro-Wilks W-test assessed the normality of the distributions. The data were analyzed by descriptive statistics and comparisons between sides, groups and genders were performed using paired or unpaired $t$ tests or Mann-Whitney tests, when indicated, considering the respective powers $(\alpha=0.05)$. The proportions of signs and symptoms of TMD between genders in the TMDB group were evaluated by Fisher's exact test. Statistical tests were two-tailed, and a $p$ value $<0.05$ was considered statistically significant.

\section{Results}

There were no MBF differences between sides so the corresponding values were averaged. They are presented in Graph 1 with their standard error of the mean (SEM) values. The respective $p$ values are in Table 1, showing that the TMDB women had significantly lower values than the others. Men had greater MBF values than women in both groups; nevertheless, men in the TMDB group had MBF values similar to those of both genders in the control group. The test powers produced while comparing TMDB women to the sub-groups was 1.0; while comparing genders in the control group, 0.5; and while comparing TMDB men to control men, 0.6.

The mean stress scores, SEM values and $p$ values inter-groups are presented in Graph 2 and Table 1, respectively. Women in the control group presented significantly less stress than did both genders in the TMDB group.

The clinical signs observed in the TMDB group and the proportions for genders, as well as the prevalence of subjective symptoms, are shown in Tables 2 and 3.

\section{Discussion}

A sample comprised of young adults with TMD and bruxism was selected with the aim of associating these characteristics with bite force magnitude, and comparing the results with those of matched healthy control subjects. The results demonstrated that TMD associated with bruxism in women decreased the magnitude of bite force in relation to men in the TMDB group and to men and women in the control group (Graph 1, Table 1). Between men 


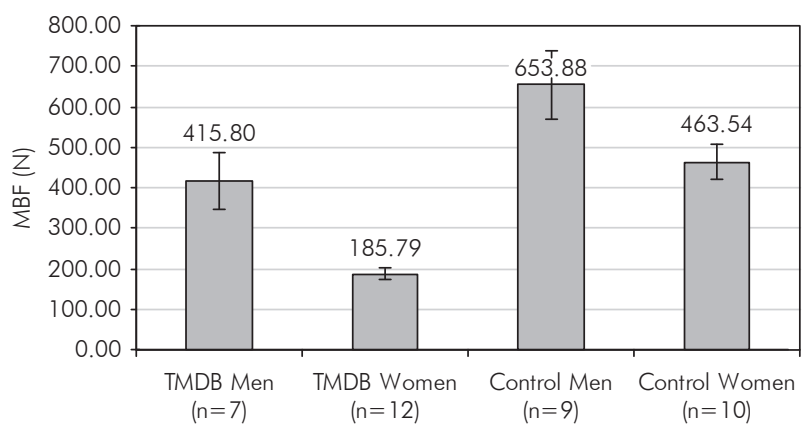

Graph 1 - Mean values of MBF (N) for the TMDB and control groups. MBF: maximal bite force. TMDB: temporomandibular disorders and bruxism.

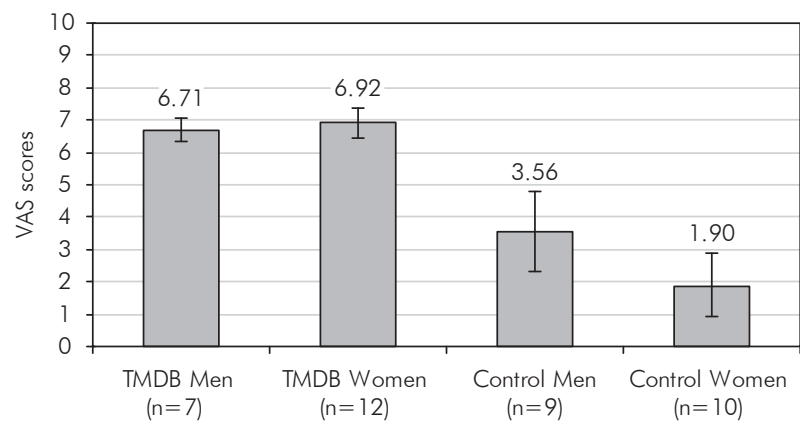

Graph 2 - Mean values of VAS for stress in the TMDB and control groups. VAS: visual analogical scale. TMDB: temporomandibular disorders and bruxism.

Table 1 - $p$ values between subgroup comparisons of MBF and VAS scores.

\begin{tabular}{|c|c|c|c|c|c|c|}
\hline Groups & $\begin{array}{c}\text { TMDB ô versus } \\
\text { TMDB } q\end{array}$ & $\begin{array}{c}\text { TMDB ơ versus } \\
\text { Control } \delta\end{array}$ & $\begin{array}{l}\text { TMDB ô versus } \\
\text { Control } q\end{array}$ & $\begin{array}{c}\text { TMDB } q \text { versus } \\
\text { Control } \sigma^{\lambda}\end{array}$ & $\begin{array}{l}\text { TMDB } q \text { versus } \\
\text { Control } q\end{array}$ & $\begin{array}{c}\text { Control ô versus } \\
\text { Control } q\end{array}$ \\
\hline MBF $p$ & $0.011 \dagger$ & $0.059 \ddagger$ & $0.591 \ddagger$ & $<0.001+$ & $<0.001 \dagger$ & $0.060 \neq$ \\
\hline VAS $p(t)$ & 0.767 & 0.169 & 0.010 & 0.065 & 0.003 & 0.307 \\
\hline
\end{tabular}

$\dagger=$ Mann-Whitney test. $\ddagger=$ Unpaired t-test. MBF: maximal bite force. VAS: visual analogical scale. TMDB: temporomandibular disorders and bruxism.

Table 2 - Proportion of clinical signs according to gender in the TMDB group.

\begin{tabular}{l|r|r|r|r|c}
\hline \multirow{2}{*}{\multicolumn{1}{c|}{ Pain }} & \multicolumn{2}{c|}{$\begin{array}{c}\text { Men } \\
(\mathrm{n}=7)\end{array}$} & \multicolumn{2}{c|}{$\begin{array}{c}\text { Women } \\
(\mathrm{n}=12)\end{array}$} & \multirow{2}{*}{$\mathrm{p}$} \\
\cline { 2 - 5 } & $\mathrm{n}$ & $\%$ & $\mathrm{n}$ & $\%$ & \\
\hline Deep Masseter & 6 & 86 & 12 & 100 & $\mathrm{~ns}$ \\
\hline Superficial Masseter & 2 & 29 & 11 & 92 & $0.001^{*}$ \\
\hline Deep Temporalis & 1 & 14 & 7 & 58 & $\mathrm{~ns}$ \\
\hline Sternocleidomastoideus & 3 & 43 & 11 & 92 & $0.038^{*}$ \\
\hline Medial Pterygoid & 1 & 14 & 7 & 58 & $0.002^{*}$ \\
\hline Temporomandibular joint & 3 & 43 & 9 & 75 & $\mathrm{~ns}$ \\
\hline
\end{tabular}

*Statistically significant (Exact Fisher's test). ns: not significant. TMDB: temporomandibular disorders and bruxism.

of both groups there was no statistical difference in MBF (Table 1), in spite of patients with TMD having been reported to have lower maximum bite force values than those of healthy subjects. ${ }^{2,13}$ This finding could be attributed to men generally reporting greater pain thresholds and tolerance. ${ }^{9}$ It may thus be that the presence of TMD had not influenced muscle strength in the studied sample. Conversely, the number of men in the control group could be considered as an influencing factor and a limitation
Table 3 - Proportion of subjective symptoms according to gender in the TMDB group.

\begin{tabular}{l|c|c|c|c|c}
\hline \multirow{2}{*}{\multicolumn{1}{c|}{ Symptoms }} & \multicolumn{2}{c|}{$\begin{array}{c}\text { Men } \\
(\mathrm{n}=7)\end{array}$} & \multicolumn{2}{c|}{$\begin{array}{c}\text { Women } \\
(\mathrm{n}=12)\end{array}$} & \multirow{2}{*}{$\mathrm{p}$} \\
\cline { 2 - 5 } & $\mathrm{n}$ & $\%$ & $\mathrm{n}$ & $\%$ & \\
\hline Headache & 6 & 86 & 7 & 58 & $\mathrm{~ns}$ \\
\hline $\begin{array}{l}\text { Teeth grinding or teeth } \\
\text { clenching }\end{array}$ & 7 & 100 & 12 & 100 & $\mathrm{~ns}$ \\
\hline $\begin{array}{l}\text { Facial/teeth/head pain } \\
\text { upon waking up }\end{array}$ & $4^{*}$ & 57 & $12 *$ & 100 & 0.029 \\
\hline Stress & 7 & 100 & 12 & 100 & $\mathrm{~ns}$ \\
\hline
\end{tabular}

*Statistically significant (Exact Fisher's test). ns: not significant. TMDB: temporomandibular disorders and bruxism.

of this study, since the test powers were moderate upon comparing this sub-group with control women and TMDB men.

The proportion of women in the TMDB group with pain in some muscles (superficial masseter, sternocleidomastoideus, and medial pterygoid) was significantly higher than that of men in the same group (Table 2); and so was the proportion of women with facial/teeth/head pain upon waking up, which was presented by all women in the TMDB group 
(Table 3). Decreased bite force was correlated with TMD in women, primarily those with muscle tenderness. ${ }^{6}$ Maximum bite force can be reduced by pain in jaw-closing muscles or in the TMJ, ${ }^{17}$ thus the present results corroborate those of other authors. ${ }^{6,17} \mathrm{On}$ the other hand, patients with bruxism showed excessively large biting forces for each given submaximal load, ${ }^{21}$ while nocturnal bite force during bruxism can exceed the amplitude of maximum voluntary bite force during the daytime in patients without TMD. ${ }^{23}$ Conversely, Cosme et al. ${ }^{8}$ (2005) did not find difference in maximal bite force between young dentate adults with or without bruxism. Thus, in view of the findings of the present study, it is possible to consider that the presence of pain is associated with marked functional impairment that may be a result of reflex adaptation and long-term hypoactivity of the jaw muscles, as also previously stated, ${ }^{13}$ thus decreasing MBF in women despite the presence of bruxism.

In principle, the strength of the mandibular elevator muscles in terms of maximum bite force varies in much the same way for age and gender. ${ }^{5,12}$ The gender-related difference found in bite force may be a result of anatomic differences. Men's masseter muscles have type II fibers with larger diameter and sectional area than those of women, suggesting that hormonal differences might contribute to the composition of the muscle fibers. ${ }^{12}$

Nevertheless, in the present study, MBF for men in the TMDB group was similar to that of men and women in the control group. In contrast, women in the TMDB group had significantly lower bite forces than those in the control group (Graph 1), suggesting that they were more affected. These outcomes could corroborate the evidence of gender differences in pain perception, as women have been reported to show more clinical pain, lower pain threshold and tolerance levels than men and are more vulnerable to the development and maintenance of musculoskeletal pain conditions. ${ }^{9}$ There is a hypothesis that the higher prevalence of chronic orofacial pain in women is a result of gender differences in generic pain mechanisms and of as-yet unidentified factors, unique to the craniofacial system. ${ }^{9}$ The gender and age distribution of TMD suggested a possible link between its pathogenesis and the female hormonal axis. ${ }^{28}$ In addition, the hypothesis that the overwhelming majority of patients treated for TMD are women could suggest an influence of the sexual hormone role in TMD. The severity of symptoms is also related to the patient's age. Pain onset tends to occur after puberty and peaks in the reproductive years ${ }^{22}$, with the highest prevalence occurring in women aged 20-40 years. ${ }^{15}$

Stress is known to be an initiating, predisposing and perpetuating factor for physical impairment, psychological symptoms and sleep disorders, ${ }^{1}$ whereas bruxism has been considered to be closely associated with TMD. ${ }^{25}$ The outcomes of the selfreported stress (Graph 2, Table 1) showed that only women in the control group presented significantly lower stress scores than those of the other subjects, agreeing with the findings of Lobbezoo et al. ${ }^{18}$ (2006) according to which the exact contribution of stress to bruxism remains a subject of debate, as the role of psychological factors differs between individuals and is probably smaller than previously assumed in its etiology. When bruxism is present due to emotional stress, the individual can develop constant tooth clenching, leading to alterations in the normal physiological process of the masticatory muscles. The capability of the stomatognathic system to adapt physiologically after alterations depends on the individual's system. For some, it is possible to overcome stress without pathologic manifestations, which could have occurred with the men of the control group. Therefore, factors like perceived stress should be taken into account when treating bruxism-related temporomandibular pain. ${ }^{1}$

\section{Conclusions}

In the present study, the maximal bite force was reduced in women with TMD and bruxism, as they presented more signs and symptoms. Men presented higher bite force values than those of women in both groups, but the presence of TMD and bruxism did not significantly decrease men's bite force. Stress was not an influencing factor on TMD and bruxism among men.

\section{Acknowledgements}

R.A.P. was a CNPq/PIBIC scholarship holder when the present study was conducted. 


\section{References}

1. Ahlberg J, Könönen M, Nissinen M, Rantala M, Sarna S, Lindholm $\mathrm{H}$ et al. Self reported stress among multiprofessional media personnel. Occup Med. 2003;53(6):403-5.

2. Ahlberg JP, Kovero OA, Hurmerinta KA, Zepa I, Nissinen MJ, Kononen MH. Maximal bite force and its association with signs and symptoms of TMD, occlusion, and body mass index in a cohort of young adults. Cranio. 2003;21(4):248-52.

3. American Sleep Disorders Association. ICSD - International Classification of Sleep Disorders, revised: Diagnostic and Coding Manual. Rochester: American Sleep Disorders Association; 1997.

4. Baba K, Haketa T, Clark GT, Ohyama T. Does tooth wear status predict ongoing sleep bruxism in 30-year-old Japanese subjects? Int J Prosthodont. 2004;17(1):39-44.

5. Bakke M, Holm B, Jensen BL, Michler L, Moller E. Unilateral, isometric bite force in 8-68-year-old women and men related to occlusal factors. Scand J Dent Res. 1990;98(2):149-58.

6. Bonjardim LR, Gaviao MB, Pereira LJ, Castelo PM. Bite force determination in adolescents with and without temporomandibular dysfunction. J Oral Rehabil. 2005;32(8):577-83.

7. Clark GT, Beemsterboer PL, Rugh JD. Nocturnal masseter muscle activity and the symptoms of masticatory dysfunction. J Oral Rehabil. 1981;8(3):279-86.

8. Cosme DC, Baldisserotto SM, Canabarro S de A, Shinkai RS. Bruxism and voluntary maximal bite force in young dentate adults. Int J Prosthodont. 2005;18(4):328-32.

9. Dao TT, LeResche L. Gender differences in pain. J Orofac Pain. 2000;14(3):169-84.

10. Dworkin SF, LeResche L. Research diagnostic criteria for temporomandibular disorders: review, criteria, examinations and specifications, critique. J Craniomandib Disord. 1992;6(4):301-55.

11. Fonseca DM. Disfunção craniomandibular (DCM): diagnóstico pela anamnese [Dissertação de Mestrado]. Bauru: Faculdade de Odontologia de Bauru da USP; 1992.

12. Garner LD, Kotwal NS. Correlation study of incisive biting forces with age, sex, and anterior occlusion. J Dent Res. 1973;52(4):698-702.

13. Hansdottir R, Bakke M. Joint tenderness, jaw opening, chewing velocity, and bite force in patients with temporomandibular joint pain and matched healthy control subjects. J Orofac Pain. 2004;18(2):108-13.

14. Johansson A. A cross-cultural study of occlusal tooth wear. Swed Dent J. 1992;86 Suppl:1-59.
15. Kuttila M, Niemi PM, Kuttila S, Alanen P, Le Bell Y. TMD treatment need in relation to age, gender, stress, and diagnostic subgroup. J Orofac Pain. 1998;12(1):67-74.

16. Lavigne GJ, Kato T, Kolta A, Sessle BJ. Neurobiological mechanisms involved in sleep bruxism. Crit Rev Oral Biol Med. 2003;14(1):30-46.

17. Liu ZJ, Yamagata K, Kasahara Y, Ito G. Electromyographic examination of jaw muscles in relation to symptoms and occlusion of patients with temporomandibular joint disorders. J Oral Rehabil. 1999;26(1):33-47.

18. Lobbezoo F, Van Der Zaag J, Naeije M. Bruxism: its multiple causes and its effects on dental implants - an updated review. J Oral Rehabil. 2006;33(4):293-300.

19. Manfredini D, Cantini E, Romagnoli M, Bosco M. Prevalence of bruxism in patients with different research diagnostic criteria for temporomandibular disorders (RDC/TMD) diagnoses. Cranio. 2003;21(4):279-85.

20. Manfredini D, Landi N, Fantoni F, Segu M, Bosco M. Anxiety symptoms in clinically diagnosed bruxers. J Oral Rehabil. 2005; 32(8):584-8.

21. Mäntyvaara J, Sjöholm T, Kirjavainen T, Waltimo A, Iivonen M, Kemppainen P et al. Altered Control of submaximal bite force during bruxism in humans. Eur J Appl Physiol Occup Physiol. 1999;79(4):325-30.

22. Meisler JG. Chronic pain conditions in women. J Women's Health. 1999;8(3):313-20.

23. Nishigawa K, Bando E, Nakano M. Quantitative study of bite force during sleep associated bruxism. J Oral Rehabil. 2001;28(5):485-91.

24. Phillips JM, Gatchel RJ, Wesley AL, Ellis E $3^{\text {rd }}$. Clinical implications of sex in acute temporomandibular disorders. J Am Dent Assoc. 2001;132(1):49-57.

25. Pierce CJ, Chrisman K, Bennett ME, Close JM. Stress, anticipatory stress, and psychologic measures related to sleep bruxism. J Orofac Pain. 1995;9(1):51-6.

26. Pigno MA, Hatch JP, Rodrigues-Garcia RC, Sakai S, Rugh JD. Severity, distribution, and correlates of occlusal tooth wear in a sample of Mexican-American and European-American adults. Int J Prosthodont. 2001;14(1):65-70.

27. Rugh JD, Ohrbach R. Occlusal parafunction. In: Mohl N, ZarbGA, Carlsson GE, Rugh JD. A Textbook of occlusion. Chicago: Quintessence; 1988. p. 249-61.

28. Warren MP, Fried JL. Temporomandibular disorders and hormones in women. Cells Tissues Organs. 2001;169(3):18792. 